\title{
Erratum
}

\section{Antibiotic prescription during the COVID-19 pandemic: a biphasic pattern - ERRATUM}

In the above mentioned article by Abelenda-Alonso et $\mathrm{al}^{1}$, the wrong figure file was used for Figure 1 in the final published version of record. The correct Figure 1 appears below. The publisher apologizes for the error.

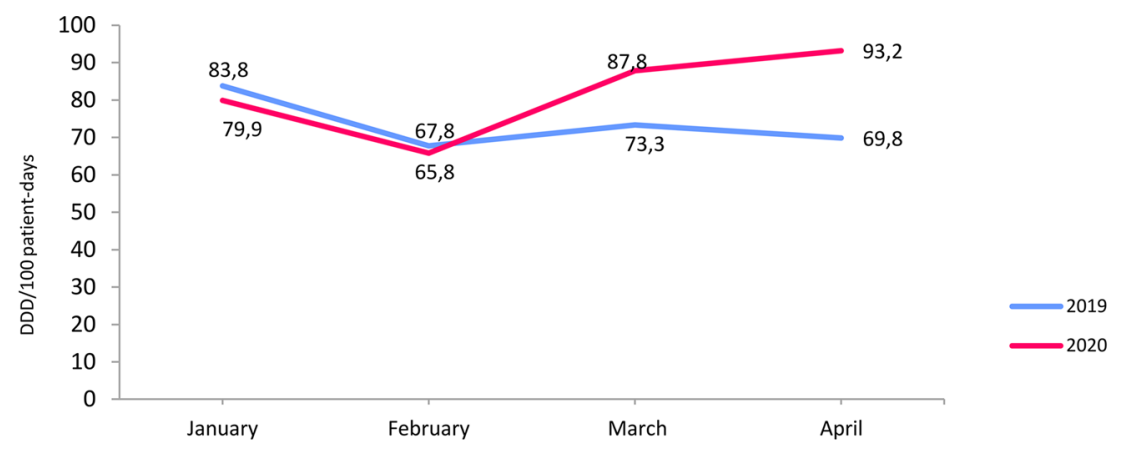

Amoxicillin/clavulanate
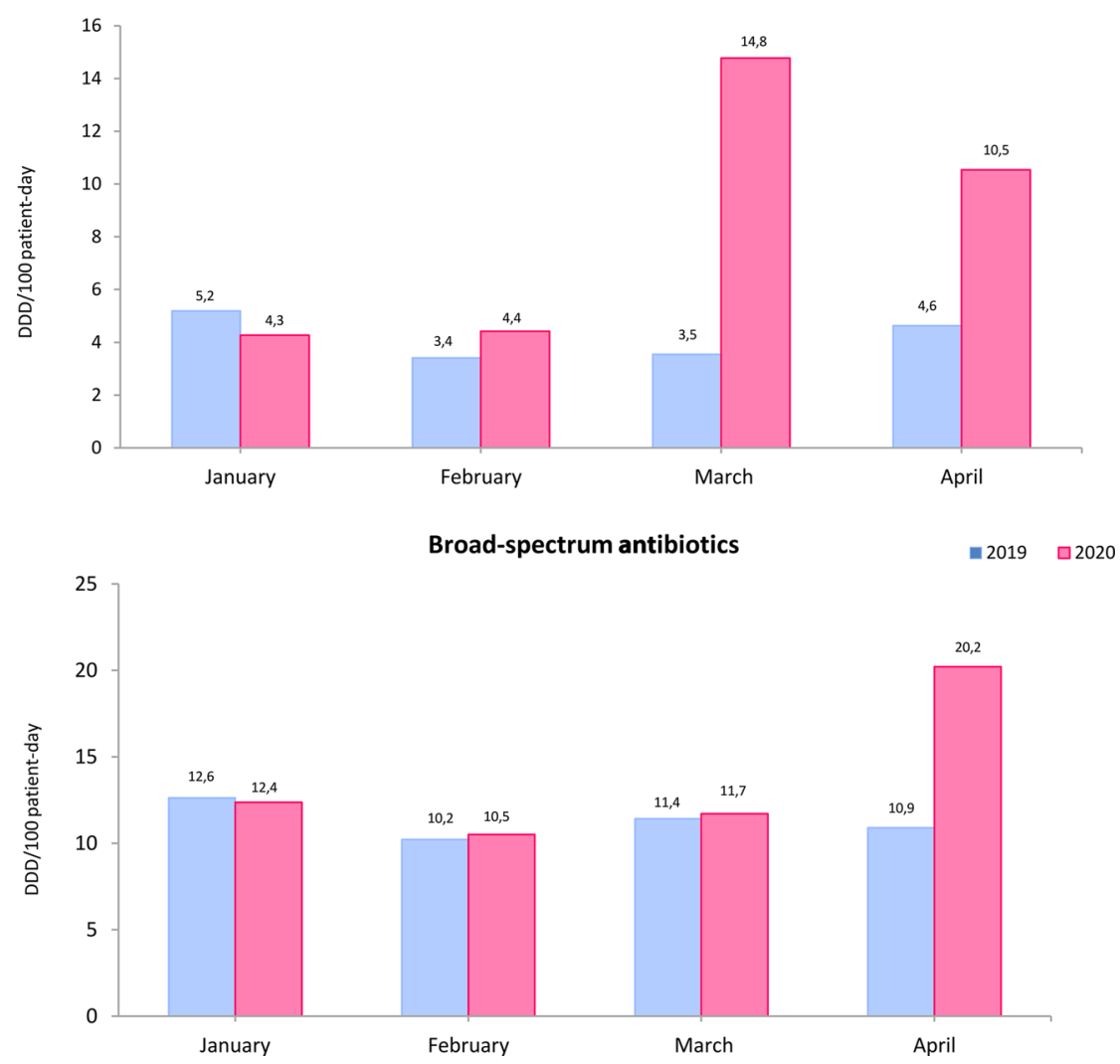

Fig. 1. Total antimicrobial consumption and comparative consumption of a amoxicillin/clavulanate and broad-spectrum antibiotics during the first 4 months of 2019 and 2020. Broadspectrum antibiotics included cefepime, piperacillin/tazobactam, meropenem, imipenem, and ertapenem. Note. DDD, defined daily dose.

\section{Reference}

1. Abelenda-Alonso G, Padullés A, Rombauts A, et al. Antibiotic prescription during the COVID-19 pandemic: a biphasic pattern. Infect Control Hosp Epidemiol 2020 July 30 [Epub ahead of print]. doi: 10.1017/ice.2020.381 